\title{
Movimentos antiglobalização e cooperação securitária na União Européia
}

\author{
Carlos S. Arturi*
}

As manifestações antiglobalização econômica de Seattle, Praga, Nice, Gênova e as três edições do Fórum Social Mundial em Porto Alegre (respectivamente em 2001, 2002 e 2003), atestam o forte crescimento dos movimentos de contestação política de uma ordem mundial baseada, de modo quase exclusivo, nas dimensões econômica e intergovernamental. A indefinição e os conflitos da nova ordem mundial após a Guerra Fria estimularam igualmente o surgimento e a manifestação destes movimentos transnacionais, onde encontra-se uma ampla diversidade de grupos tanto no que diz respeito as suas formas de organização, atuação e objetivos, quanto aos recursos de que dispõem. Adota-se o qualificativo de "altermundialistas" para estes movimentos contestatórios, pois muitos deles propõem uma mundialização alternativa, ou "neoglobalização", baseada em premissas diferentes daquelas

* Professor do Departamento de Ciência Política e dos Programas de Pós-Graduação em Ciência Política e em Relações Internacionais da Universidade Federal do Rio Grande do Sul. Realizou seu doutorado no Institut d'Etudes Politiques de Paris (Sciences Po) e tem focalizado sua pesquisa sobre democracia e política internacional. Publicou Le Brésil: une tentative de démocratisation octroyée (2000), co-organizou Democracia e Governança Mundial: que regulações para o século XXI? (2002) e é co-autor do artigo El Foro Social Mundial como nuevo espacio de contestación y control democrático (2004). carlos.arturi@ufrgs.br

Civitas v. 4

Porto Alegre n. 2 jul.-dez. 2004 p. $285-302$ 
que movem a atual expansão global do capitalismo. Sua emergência e grande repercussão nos últimos anos exigem repensar o papel e as funções de atores não-governamentais e dos Estados nas relações internacionais.

Nesta perspectiva, este paper é o resultado de um estudo preliminar para uma pesquisa de pós-doutoramento junto ao Instituto de Ciências Sociais (ICS) da Universidade de Lisboa, cuja finalidade principal é a de compreender e analisar as respostas e reações dos Estados nacionais à emergência de atores não-governamentais que se opõem à ordem mundial atual, buscando vigiá-los e, eventualmente, reprimi-los. Trata-se aqui, portanto, de examinar alguns dados empíricos já coletados e apresentar algumas questões de cunho teórico sobre o tema que orientam aquela pesquisa, em andamento. $\mathrm{O}$ trabalho possui, assim, um caráter essencialmente prospectivo. ${ }^{1}$

O estudo sobre as reações interestatais provocadas pela contestação internacional possui a particularidade de tratar de um fenômeno ilustrativo da erosão da centralidade do estado nas relações internacionais, pois a oposição à globalização é dirigida e organizada por movimentos transnacionais e nãoestatais, o que afeta a capacidade dos Estados de agir e fixar objetivos políticos com a autonomia de outrora em arenas internacionais não estratégicomilitares (Villa, 1999). A pesquisa, uma vez finalizada, deverá contribuir para o avanço científico sobre o processo de globalização - cujas dimensões políticas são ainda pouco estudadas - ao melhor iluminar as relações, em âmbito mundial, entre os novos atores transnacionais e os Estados, e destes últimos entre si, bem como aquilatar os constrangimentos, originados pela articulação securitária entre os estados, para o estabelecimento de relações internacionais mais pacíficas e regimes nacionais mais democráticos.

A globalização econômica, a proliferação de atores internacionais nãoestatais e o fim da Guerra Fria provocaram, entre outros fenômenos, o fim do status que gozavam os estados nacionais de serem praticamente os únicos protagonistas das relações internacionais, pois doravante devem levar em consideração e relacionar-se com muitos outros atores não-estatais de atuação transnacional (Rosenau, 1990). Nesta perspectiva, quais são os conflitos e articulações que se desenham entre estados nacionais e organizações não

1 A pesquisa insere-se igualmente no âmbito do Grupo de Pesquisa do CNPq Contestação Internacional e Controles Democráticos, do qual o autor é líder. 
estatais? Quais são os atores relevantes? O que pretendem? Como se organizam e atuam? Quais as respostas institucionais e coercitivas dos estados aos movimentos de contestação à globalização econômica neoliberal? Quais são os órgãos, instituições e acordos interestatais e/ou comunitários utilizados para vigiar, controlar e/ou reprimir estes movimentos de contestação internacional? Finalmente, qual o impacto na teoria das relações internacionais e na ciência política com o advento de novos atores transnacionais que contestam a globalização e a hegemonia dos estados no cenário mundial? Estas questões, que orientam a pesquisa, serão comentadas e analisadas neste trabalho.

A hipótese principal do trabalho é a de que a constituição de uma governança securitária interestatal - que busca vigiar, controlar e, eventualmente, reprimir os movimentos antiglobalização - é a reação dos estados nacionais à emergência da contestação internacional organizada. Após os atentados de 11 de setembro, verificou-se um recrudescimento repressivo e normativo, bem como a intensificação da cooperação policial e de inteligência intergovernamentais visando ao controle e à contenção daqueles movimentos. Outra hipótese, de caráter teórico, é a de que a dinâmica dos conflitos entre movimentos de contestação antiglobalização e a reação a eles articulada por estados nacionais, sobretudo no âmbito da União Européia, prefiguram uma dimensão verdadeiramente mundial da política internacional, isto é, pressupõem a ação ativa de atores transnacionais não-estatais e arranjos institucionais e operacionais interestatais para confrontá-los.

A União Européia (EU) é privilegiada na análise porque a articulação institucional entre seus membros, inclusive nos aspectos relativos às questões de defesa, segurança e justiça, encontra-se mais avançada que em qualquer outra comunidade política. Em segundo lugar, a UE constitui um exemplo de comunidade regional exitosa, capaz de introduzir uma dimensão média entre o espaço nacional e o espaço mundial, bem como ultrapassar uma oposição por demais rígida entre território e interações entre diversos atores nãoestatais e internacionais (Smouts, 1998, 26). De fato, o estudo das relações interestatais na UE possibilita-nos enfrentar uma questão fundamental: a natureza dos acordos e cooperação prática entre os Estados da comunidade nas questões de segurança enquadra-se no escopo tradicional das relações interestatais ou prefigura uma política internacional que se constitui "além do Estado", de caráter verdadeiramente mundial? 
A primeira parte do trabalho, de viés mais teórico, tratará das relações entre globalização, Estados nacionais e movimentos de contestação transnacionais, tendo em vista problematizar o objeto da pesquisa. Já as medidas de controle e repressão direcionados contra o movimento antiglobalização na União Européia serão estudados, neste momento, através da análise das declarações e diretivas de chefes de governo europeus sobre os protestos e das ações concretas tomadas por ocasião das grandes manifestações antiglobalização referidas acima. ${ }^{2}$ Finalmente, à luz da análise preliminar dos dados já obtidos, avançaremos algumas considerações de ordem teórica e empírica sobre o tema, que constituem pistas para a continuidade da pesquisa.

\section{Globalização, Estados nacionais e movimentos de contestação internacionais}

O processo de globalização do capitalismo nas últimas décadas está baseado, segundo Tarrow, em dois processos concomitantes: a internacionalização política, através do surgimento de atores, instituições e redes transnacionais, e a integração econômica, pelo crescimento vertiginoso do comércio internacional, dos meios de comunicação e da integração financeira (Tarrow, 2002). Neste sentido, a globalização permite a estruturação da contestação internacional, ao criar as estruturas de oportunidade - as políticas neoliberais são gestadas e articuladas a partir de instituições multilaterais (FMI, OMC, Banco Mundial, etc.) - e ao incentivar e produzir as ocasiões para a ação dos atores transnacionais antiglobalização, que reúnem-se e manifestam-se nos grandes eventos patrocinados por aquelas instituições (Ayres, 2002). Adotamos aqui a definição de Fouguier para os "movimentos de contestação da mundialização": "nebulosa de grupos e indivíduos que denunciam as conseqüências negativas do processo atual de mundialização, por eles descrito como mundialização 'liberal' ou 'neoliberal' e que esforçam-se para modificar seu curso num sentido mais conforme a seus ideais e a seus objetivos, por meio de diferentes tipos de ação" (Fouguier, 2002, p. 843). A heterogeneidade dos movimentos contestatórios transnacionais - abrangendo desde organi-

2 O exame da legislação, das instituições multilaterais e dos arranjos operacionais articulados pelas agências de segurança e informações estatais daquela comunidade será realizado durante o pós-doutoramento no ICS da Universidade de Lisboa, entre Setembro de 2004 e Março de 2005 . 
zações anarquistas e de revolucionários de esquerda até outras mais "pragmáticas", centradas em reivindicações específicas, e incluindo também reformistas da ordem mundial, sejam eles "internacionalistas" ou mais "soberanistas" - não impede que estas grupos unam-se por ocasião das grandes manifestações e campanhas de protesto antiglobalização ${ }^{3}$. Além dos efeitos negativos da globalização econômica atual, o surgimento com força de tais movimentos no cenário internacional deve-se também ao déficit democrático da globalização e aos limites da democracia representativa no interior dos estados nacionais (Nye, 2001; Montès, 2001).

A conjuntura internacional caracteriza-se pela crise da antiga ordem mundial, moldada pela bipolaridade da Guerra Fria e de transição para outra que não está ainda configurada, mas que já revela-se mais instável e mais complexa que a anterior. De fato, permanecem, no início do século XXI, a hierarquia de poder e a disputa acirrada entre os estados nacionais, os conflitos armados de toda ordem, bem como as mazelas da globalização econômica. Sob a perspectiva do estudo das relações internacionais, a globalização, os movimentos que a contestam e o surgimento de novos atores internacionais (ONGs, blocos regionais, grandes empresas transnacionais, fóruns, mídia, redes científicas, etc.) foram responsáveis por um grande impacto teórico e metodológico: o questionamento do papel hegemônico que desfrutava o estado, como ator mais relevante, na maioria das análises sobre política internacional desde o fim da Segunda Guerra, influenciadas pela escola realista. Com efeito, no início dos 1970, Keohane e Nye desafiaram frontalmente o modelo "estado-centrado" então prevalecente na literatura especializada, ao considerá-lo inadaptado para o estudo da emergência de atores transnacionais autônomos em relação aos estados nacionais, o que implica numa multiplicação de trocas entre os estados e entre estes e os outros atores transnacionais (Keohane e Nye, 1971). A interdependência e a pluralidade de atores internacionais foram os elementos centrais do paradigma da "política mundial" que propuseram, como denominação mais precisa do que política "internacional", demasiado vinculado às relações entre estados.

3 Segundo Keck e Sikkink (1997), os movimentos de contestação antiglobalização compartilham algumas características em comum, tais como o de serem movidos por princípios, acreditarem que ação dos indivíduos podem ser fundamentais para atingir os resultados almejados, utilizarem a informação como um de seus principais meios de luta e aplicarem estratégias políticas para atingirem seus objetivos. 
Conceitos como os de "sociedade civil mundial" e "governança global" surgem em análises que tentam formular novos referenciais teóricos, freqüentemente com viés normativo, para compreender um espaço político e atores verdadeiramente mundiais. A constituição de um espaço público mundial e democrático defronta-se, todavia, com uma série de problemas: a quase inexistência de fóruns de encontro e debate entre os diversos atores mundiais; a crise do intergovernamentalismo e do multilateralismo acentuada depois dos ataques de 11 de setembro e da invasão anglo-americana do Iraque; a heterogeneidade de propostas e de atores que integram a chamada corrente alternativa e contestatória; os diferentes estágios de desenvolvimento político das democracias nacionais que influenciam diretamente a capacidade de mobilização e o potencial de participação dos agentes da sociedade civil organizada; a tendência de algumas ONGs de articularam-se diretamente com instituições internacionais e grandes empresas, em detrimento de órgãos estatais, sobretudo nos países mais pobres; a falta de legitimidade de muitas associações e ONGs que se auto-intitulam representantes de setores sociais; a inclinação à utilização da violência por alguns grupos de contestadores da ordem mundial atual (Arturi, 2002).

Apesar da intensidade dos debates sobre a teoria das relações internacionais, enfoques analíticos que associam em doses variadas as teorias "realistas", "institucionalistas" e "construtivistas" são crescentemente adotadas na explicação da mundialização. Preferimos neste trabalho adotar uma abordagem 'realista' atenuada que, embora considere os Estados como atores principais das relações internacionais, reconheça que o surgimento de novos atores transnacionais diminuiu seu poder e aumentou a influência das instituições internacionais e dos movimentos transnacionais (Castro, 2001). Nesta perspectiva e visando os objetivos da pesquisa, uma das teses centrais de Charles Tilly (1996) sobre os conflitos e as rebeliões, bem como sobre a repressão e a negociação entre contestadores e governantes - que foram essenciais para constituição e prevalência do estado nacional moderno nos últimos séculos - revela-se particularmente importante para a análise da contestação internacional e das medidas de vigilância, contenção e repressão destes movimentos pelos estados nacionais. No que diz respeito à "contestação popular", este autor afirma, baseado em extensa pesquisa histórica, que os indivíduos e os grupos aprendem a reivindicar aos poderosos, formando um "repertório de ações coletivas" que acompanham o desenvolvimento do 
capitalismo e do estado nacional no ocidente. Assim, anteriormente à industrialização e à urbanização, as formas de contestação foram mais locais e menos organizadas, mas a partir do século XIX, tornaram-se de âmbito mais nacional. A resposta do Estado e das elites nacionais foi também mais centralizada, quer quando reprimiu estes movimentos com eficácia, quer quando com eles negociou franquias e direitos políticos, estabelecendo novos canais de ação coletiva e instituições responsáveis por novas formas de contestação não-violentas, como a legalização de partidos de esquerda, por exemplo (Tilly, 1986). A estes dois "repertórios de ação coletiva" - local e nacional -, o autor referiu-se ao terceiro, que corresponde aos movimentos transnacionais, simultaneamente de alcance mundial e deslocalizados (Tilly, 1992).

Partimos desta conclusão de Charles Tilly sobre a centralidade dos conflitos e da mobilização coletiva para a ruptura ou reforma profunda de uma ordem política e para o desenvolvimento das instituições, para problematizar e atualizar o tema em uma dimensão mundial; e compreender, assim, as expressões da contestação internacional antiglobalização e a reação dos estados e dos órgãos multilaterais à sua emergência nos últimos anos. Admite-se que, face aos conflitos e à contestação de movimentos organizados, bem como à presença de novos atores internacionais, os estados nacionais procurem dar uma resposta - coerção e/ou reformas - também de âmbito mundial, articulando entre si políticas e práticas de segurança e inteligência, que certamente darão lugar a novas formas de coerção em escala supra-estatal e/ou a instituições políticas de caráter mundial, atualizando o "repertório de ações coletivas" e as instituições políticas, em tempos de globalização, isto é, sua expansão e internacionalização. Com efeito, a contestação, a coação e a jurisdicionalização da política internacional sofreram notável desenvolvimento nos últimos anos, o que provocou uma mudança de nível de atuação, do nacional ao mundial, tanto dos movimentos antiglobalização como dos órgãos de inteligência e coerção dos estados.

A reação dos Estados, sobretudo das grandes potências, à contestação internacional antiglobalização está sujeita a diferentes interpretações, que não serão objeto de análise neste trabalho. De qualquer modo, a expansão e articulação interestatais de agências de inteligência e segurança representa um risco para a democracia nas relações internacionais e no interior mesmo dos espaços nacionais, pois freqüentemente implica o recuo da diplomacia, a predominância do Executivo e a falta de accountability. Sobre este ponto, 
podemos admitir que a expansão, aproximação e crescente sinergia entre as unidades de inteligência policial e de agências de segurança nacional, que Cepik (2003) constatou no interior dos estados nacionais nas últimas décadas, podem também ocorrer em escala internacional, entre agências e instituições de vários estados; colaboração mais ou menos organizada, mais ou menos formal, conforme cada caso.

\section{Grandes protestos antiglobalização e reação interestatal na União Européia}

O fim da Guerra Fria provocou em muitos analistas um forte otimismo quanto às chances de diminuição dos conflitos, assim como proeminência e a autonomia dos atores transnacionais nas relações internacionais. No entanto, "a idade de ouro dos movimentos transnacionais se situou, na verdade, entre a queda do Muro de Berlim e o 11 de Setembro [...]. Mas o 11 de Setembro projetou novamente à ribalta a violência legítima no interior como no exterior das fronteiras, e o Estado retomou as rédeas da besta. [...] É um período de fluxo e incerteza que favorece os grandes aparelhos de Estado" (Kemp, 2003, p. 26-27). As tentativas de contenção, por parte das forças da ordem, das manifestações antiglobalização inserem-se neste ambiente "schmittiano" da guerra contra o terrorismo.

Os estados nacionais procuram esvaziar o conteúdo político dos protestos e as causas que lhe dão origem, promovendo até mesmo sua criminalização, como ficou notório após os eventos de Gotemburgo e Gênova, em junho e julho de 2001, respectivamente. Neste sentido, destaca-se o processo de ultrasecuritização estatal que vem ocorrendo mundialmente e que sofreu um recrudescimento após os atentados do 11 de setembro de 2001. A partir deste evento, verificou-se a multiplicação de medidas jurídico-legais, bem como policiaisoperacionais - já em experimentação desde antes - que implicam o risco de criminalização dos movimentos sociais. Assiste-se à aceleração sem precedentes da transnacionalização da governança em escala mundial e, ao mesmo tempo verifica-se uma atuação dos centros de poder estatais visando a impedir uma transnacionalização correlata da contestação mundial. Na União Européia, onde o movimento antiglobalização neoliberal tem uma de suas principais bases, as redes policiais e os serviços de inteligência expandem-se, impondo uma visão da contestação social - mas também acerca de outras respostas ao processo de 
globalização neoliberal, como os grandes fluxos de imigração - como problema de segurança. Da análise das declarações de chefes de governo europeus sobre os protestos, de diretivas sobre como as autoridades devem proceder com relação aos movimentos e das ações concretas tomadas por ocasião das grandes manifestações, pode-se depreender uma tendência para a criminalização da dissidência política representada pela contestação internacional.

Os movimentos altermundialistas, com suas redes e mobilizações internacionais centradas em eventos, desterritorializam os conflitos entre estes grupos e os estados, e a "cronopolítica" substitui a geopolítica (Bigo, 1998) Assim, uma cronologia resumida e brevemente comentada das grandes manifestações de contestação à globalização permitirá delimitar melhor nosso objeto. ${ }^{4}$ Se os protestos em Seattle, em 1999, têm sido caracterizados como o batismo de fogo do movimento de contestação à globalização neoliberal, o ano de 2000, na Europa, inaugura-lhe uma nova fase. Isto se deve a três acontecimentos principais, que dotam este heterogêneo movimento de nova capacidade organizativa: o anúncio da realização do Fórum Social Mundial para janeiro de 2001, em Porto Alegre, e as mobilizações de Praga e de Nice. De 22 a 25 de junho de 2000, por ocasião da Conferência Social das Nações Unidas (também conhecida como "Copenhagem + 5"), em Genebra - Suíça -, associações, ONGs e sindicatos organizam um encontro alternativo, onde Miguel Rossetto, então vice-governador do Rio Grande do Sul, anuncia o apoio deste estado à realização, em janeiro de 2001, em Porto Alegre, do Fórum Social Mundial, proposto inicialmente por organizações do Brasil e da Europa. Ainda durante o ano de 2000, em setembro, ocorrem as mobilizações de Praga, em contraposição à reunião anual do Banco Mundial e do Fundo Monetário Internacional realizada entre os dias 26 e 28 na capital da República Tcheca. As manifestações reúnem cerca de dez mil pessoas de várias partes do continente para protestar contra as instituições do sistema de Bretton Woods. Depois de Praga, o movimento de contestação à globalização neoliberal organiza, em outubro de 2000, uma contra-conferência em Bayonne, simultaneamente à reunião do Conselho Europeu de Biarritz. Mas é no Conselho Europeu seguinte, reunido de 6 a 7 de dezembro em Nice, na França, que se sucedem fatos de suma importância para o futuro do movimento na Europa.

4 A cronologia apresentada nos parágrafos seguintes foi elaborada pelo graduando em História da UFRGS e bolsista de Iniciação Científica (CNPq) Mathias Seibel Luce, que auxiliou o autor na pesquisa preliminar (Luce, 2003). 
A reunião de Nice fora convocada tendo como pauta a adoção de um novo tratado prolongando o de Amsterdã (1997, entrada em vigência de 1999). Os movimentos sociais, por seu turno, organizam uma contra-conferência e, no dia 6 de dezembro de 2000, promovem uma grande manifestação em torno do tema da Europa social. A manifestação é encabeçada pela Confederação Européia de Sindicatos (CES). A importância de Nice para o estudo da governança e da contestação na Europa se dá pelo fato de figurar como o início efetivo da adoção de medidas conjuntas, em nível de U.E., para dificultar ou impedir as manifestações de contestação à globalização. Embora medidas com este objetivo possam ter sido tomadas anteriormente, o caráter definidor do Conselho Europeu de Nice reside em que os governos europeus tenham decidido, nesta ocasião, suspender os Acordos de Schengen durante o período do encontro, visando conter a chegada de manifestantes de outros países. $\mathrm{O}$ Acordo de Schengen foi assinado em 1985 por Alemanha, França e os países do Benelux e "[...] previa a livre circulação de todos que residem ou viajam nos seus territórios, por meio da supressão gradual dos controles nas fronteiras comuns. Todavia, [...] esse acordo foi concretizado apenas em 1990 pela assinatura da Convenção de aplicação do acordo de Schengen, que entrou em vigor em 1995. Os demais Estados da União [U.E.] aderiram a essa convenção com exceção do Reino Unido e da Irlanda, e com restrições de parte da Dinamarca" (D’Arcy, 2002, p. 163-164). Embora inicialmente estabelecido no âmbito da cooperação intergovernamental, o Acordo de Schengen foi elevado ao status comunitário quando incorporado, em 1997, ao direito da União Européia, por um protocolo anexo ao Tratado de Amsterdã, que entrou em vigência, por sua vez, em 1999. Em 25 de março de 2001, Noruega e Islândia - embora não-integrantes da U.E. - tornaram-se membros associados do Acordo de Shengen, passando a usufruir os direitos correspondentes, à exceção do de participar da tomada de decisões.

Enquanto Nice revela a primeira suspensão do Acordo de Schengen, Gotemburgo traz consigo a primeira atuação das forças policiais disparando contra os manifestantes com munição real. Este episódio ocorre por ocasião da reunião do Conselho Europeu de 14 a 16 de junho de 2001, na referida cidade sueca. Os movimentos europeus haviam preparado uma contraconferência, organizada por uma plataforma batizada de Ação de Gotemburgo, envolvendo cerca de 80 organizações, como ATTAC, organizações sindicais, Friends of the Earth, Ação Antifascista, além de partidos de es- 
querda. No dia 15, vinte mil pessoas concentram-se na praça Järn, para manifestar-se pacificamente contra as políticas neoliberais presentes no âmbito da U.E (Cfe. OSAL, 2002). Na visão dos manifestantes e da opinião pública européia, a polícia reagiu de forma desproporcional aos atos violentos de alguns provocadores - minoria entre os que protestavam - atirando balas reais contra os manifestantes e atingindo três deles, sendo um ferido gravemente. Dezenas de outros manifestantes também sofreram outros ferimentos e pelo menos 700 foram detidos. O ministro alemão do Interior, Otto Schily, impulsionou a organização de uma conferência com seus homólogos da União Européia para melhor coordenar estratégias de segurança. Esta viria a ser a reunião $n^{\circ} 82$ do Conselho de Justiça e Assuntos Internos da UE, realizada em Bruxelas em 13 de julho de 2001. Embora o documento aprovado pelos representantes reunidos defenda "o desenvolvimento de diálogos construtivos com os organizadores das manifestações para garantir que manifestações legítimas não sejam exploradas por grupos com uma agenda violenta", em outra passagem ele sugere o uso de todos os meios disponíveis para impedir o livre trânsito de indivíduos dos quais se suspeite estarem viajando "com a intenção de organizar, provocar ou participar de distúrbios graves da lei e ordem públicas".

Os eventos de Nice, Gotemburgo e Gênova formam uma linha de continuidade que abarca desde a suspensão dos direitos de livre circulação (Nice), passando pelo emprego de armas de fogo contra manifestantes (Gotemburgo) e culminando com a morte de um destes em um esquema antiprotestos que lembra teatros de operações bélicas (Gênova, julho de 2001). Como sustentam Nathalie Bayon e Jean-Pierre Massem, as jornadas de Gênova marcam o início de uma criminalização do pensamento político alternativo do movimento antiglobalização, sob a opção deliberada de reprimi-lo através da força (Bayon e Masse, 2002, p. 143).

5 Ver http://register.consillium.eu.int/pdf/em/01/st10/10916en1-pdf). Esta mesma diretiva é implementada na elaboração de listas dos manifestantes "perigosos", prática denunciada por resolução do Parlamento Europeu (Resolução 2001/2167 (INI). "Recomendation du Parlament européen au Conseil sur um espace de sécurité, de liberte et de justice: securité lors des réunions du Conseil européen et autres événements internationaux comparables. http://www3europarl.eu.int/omk/omnsapir.so/pv2?PRG=CALDOC\&FILE=011212\&LANGU). 
O surgimento de estruturas comunitárias de cooperação policial é mais um passo que se está tomando na configuração de uma unidade política supraestatal na Europa, o que implica questões importantes para as relações internacionais. Nesse sentido, os Acordos de Schengen e a criação da Europol são dois elementos fundamentais a serem analisados, com destaque para a maneira como as autoridades européias os vêm utilizando para controlar e reprimir a contestação internacional. A Agência Européia de Polícia Europol - foi criada em 1995 e entrou em operação em 1999. Com sede em Haia, visa a "melhorar a cooperação entre os Estados-membros na luta contra o terrorismo, contra o tráfico ilícito de estupefacientes e outras formas graves de crime internacional". A Europol consiste de um centro de intercâmbio e coordenação de informação - mas também de coleta e análise -, gerando inteligência sobre suspeitos de haverem cometido ou participado de infrações, assim como de pessoas sobre as quais repouse a presunção de delito. Por este caráter pró-ativo - isto é, anterior a uma infração que não se sabe ao certo se vai ocorrer - a Europol tem sido criticada como risco potencial às liberdades civis, à medida que inexistem instrumentos adequados de controle público sobre a atuação de seus agentes, que contam com prerrogativas e imunidades que podem resultar em abuso de autoridade (Paye, 2002, p. 68-70).

Quanto ao Mercosul, as relações inter-estatais visando a cooperação policial e de inteligência no combate ao crime organizado e ao terrorismo - que não serão objeto de análise neste paper - revelam-se também problemáticas. De fato, embora com um processo de integração econômica e política bem mais incipiente do que na UE, já ocorreram no Mercosul eventos como a Reunião dos Ministros da Justiça e do Interior do Mercosul, da Bolívia e do Chile, em agosto de 2000, onde alguns participantes falaram em articular as agências de segurança e informações nacionais contra o "terrorismo" e movimentos sociais. Houve também a Reunião dos Países da Alca em abril de 2001, na Argentina, quando a fronteira deste país foi fechada para os cidadãos dos países vizinhos e a repressão foi dura sobre os grupos que protestavam. No caso dos países que formam o Mercosul, o passado de cooperação entre agências nacionais de segurança e informação na região foi catastrófico para a democracia e para o respeito dos direitos humanos, como no caso exemplar da Operação Condor, protagonizada pelas polícias políticas das ditaduras do Cone Sul nos anos 1970. 


\section{Considerações finais}

O estudo do controle e repressão direcionados contra o movimento antiglobalização na União Européia visa a contribuir, do ponto de vista teórico, à reflexão sobre o monopólio legítimo da força no provimento de ordem pública nesta comunidade política em emergência. Contando já com um Parlamento Europeu com representantes independentes dos legislativos nacionais, a UE debate, no presente momento, o aprofundamento de sua integração política com o projeto de Constituição Européia em discussão. O estudo sobre a coordenação entre agências de segurança e inteligência no âmbito da União Européia também justifica-se porque apresenta-se como uma comunidade de estados, agindo em cooperação e conflito, na busca de uma maior integração e coordenação política. Nossa questão central porta exatamente sobre o estatuto desta cooperação: trata-se apenas de acordos e instituições firmados entre estados nacionais, que não alteram o mundo "westphaliano", ou trata-se da constituição das primeiras instituições realmente supra-estatais a compartilhar atributos que até então eram exclusivos dos estados nacionais, como aqueles concernentes às atividades de segurança e inteligência? No que diz respeito às relações entre instituições européias especializadas nestas atividades e os movimentos altermundialistas, a questão central para nossa pesquisa é a de verificar que padrão de relacionamento está se constituindo entre os estados, organizações regionais intergovernamentais e os atores transnacionais que contestam a ordem mundial. Em suma, qual o "repertório de ações coletivas" transnacionais que está se constituindo nos últimos anos? Acarretará mais conflitos e repressão, ou assistiremos o surgimento de instituições políticas representativas supranacionais, sobretudo na União Européia, que poderiam constituir os alicerces de uma política mundial, multidimensional e em vários níveis de atuação, onde a cisão interno/externo daria lugar ao lo$\mathrm{cal} /$ mundial?

O processo de constituição e desenvolvimento da União Européia tem sido estudado através de diversas abordagens. Alguns autores, com Stanley Hoffmann, ressaltam o caráter intergovernamental desta comunidade, onde os diferentes estados nacionais são considerados atores racionais regidos pelos princípios de hierarquia - pooled sovereignty - cuja elevada interdependência a transforma numa espécie regime internacional aprofundado (Lequesne, 1998). Nesta perspectiva, os acordos e instituições de segurança estabelecidos 
entre os governos europeus enquadra-se na teoria "neorealista", que considera a possibilidade de cooperação e de alianças entre os estados, que continuariam a perseguir seus interesses nacionais. Mas, outros autores analisam o desenvolvimento da UE através de um modelo "federalista", onde sempre estaria presente a tensão entre interesses territoriais e interesses funcionais (Sbragia, 1992). Nesta perspectiva, o desenvolvimento de instituições e práticas comunitárias em assuntos pertinentes a segurança e inteligência pode ser o embrião de estruturas estatais supranacionais, originadas pelas necessidades da interdependência dos estados nacionais, da reação à contestação internacional e dos interesses corporativos dos técnicos e agências envolvidos. Qual modelo irá prevalecer é difícil ainda de prever, e toda a ambigüidade desta indefinição pode ser sintetizada pelo comentário de um analista "realista", que não confia muito na duração da atual cooperação entre os estados europeus, mas percebe sinais da constituição de estruturas supraestatais devido à dinâmica "federalista" da UE:

À medida que a ameaça exterior (terrorismo, armas de destruição em massa) recuem, veremos as tensões entre as nações do interior se exacerbarem (entre a França e os Estados Unidos, por exemplo, entre o Reino Unido e a União Européia), e a política e a luta pelo poder retomarão seus direitos. Serão necessários, então, instrumentos novos. Os atuais são, de fato, visíveis e consensuais demais para serem solicitados eficazmente nesta nova luta pelo poder. Eles [os serviços de segurança e inteligência] flertaram com o Outro para poderem, de um dia para outro, o tratar como inimigo. Eles foram por demais inseridos em comitês transnacionais de concertação e de coordenação. Eles efetuaram operações conjuntas demais com os serviços "amigos". [...] Em uma palavra, eles não têm mais nada de uma máquina de guerra. Ora, para estar à altura da nova luta que se anuncia pelo poder, e para defender seus interesses contra os amigos-rivais, o que é necessário é contar com uma autêntica máquina de guerra (Kemp, 1998).

Certamente, a prevalência final quer da tendência "intergovernamental" quer da "federalista/mundialista" no desenvolvimento político da União Européia, sobretudo nas questões "regalianas" de segurança, justiça e inteligência, será determinada em boa medida pela dinâmica dos conflitos e/ou negociações entre os movimentos altermundialistas e os aparatos interestatais que lhes fazem face. Estas alternativas encontram-se também sob a influência conjunta e combinada dos imperativos da globalização econômica, dos conflitos externos e internos nacionais, das políticas de alianças e dos interesses corporativos das organizações interestatais. A possibilidade de uma ordem 
mundial mais pacífica e democrática depende do resultado destes conflitos na esfera política internacional, que envolve o "terceiro repertório de ações coletivas”, em construção pelos movimentos altermundialistas.

\section{Referências}

ARTURI, Carlos S. Os desafios para a instauração de uma governança mundial democrática na atual conjuntura internacional. Indicadores Econômicos FEE, v. 31, n. 1, p. 75-93, 2003.

ARTURI, Carlos S.; OLIVEIRA, Renato de. Introdução. In: MILANI, C.; ARTURI, C.; SOLINIS, G. (Orgs.). Democracia e governança mundial. Porto Alegre: UFRGS/UNESCO, p. 11-29, 2002.

AGUITON, Cristoph. Le monde nous apartient. Paris: Plon, 2001.

AMIN, Samir; HOUTARD, François. Mondialisation des résistances, l'état des luttes 2002. Forum Mondial des Alternatives, Paris: L'Harmattan, 2002.

AYRES, J. Transnational political processes and contention against the global economy. In: SMITH, J.; JOHNSTON, H. Globalization and resistance: transnational dimensions of social movements. Maryland: Rowman \& Littlefield, 2002.

BAYON, Nathalie; MASSE, Jean-Pierre. Petites impressions génoises. Chroniques quotidiennes d'une mobilisations antimondialisation. Cultures \& Conflits, Paris, n. 46, p. 143, été 2002.

BENOIT, Loïk. La lutte contre le terrorisme dans le cadre du deuxième pilier: un nouveau volet des relations extérieures de l'Union européenne. Revue du Droit de l'Union Européenne, n. 2, p. 283-313, 2002.

BERTHELET, Pierre. L'impact des événements du 11 septembre sur la création de 1'espace de liberté, de securité, et de justice. Cultures \& Conflits, Paris, n. 46, été 2002.

BIGO, Didier; GUILD, Elspeth. De Tampere à Séville, vers une ultra gouvernementalisation de la domination transnationale? Cultures \& Conflits, Paris, $\mathrm{n}$. 46, été 2002.

BIGO, D. Polices en Résaux. Paris: Presses de Sciences Po., 1996.

CASSAIGNE, Bertrand. Réflexions pour conclure. Projet, Paris, n. 252, 1997-1998.

CASTRO, Marcos Faro de. De Westphalia a Seattle: a teoria das relações internacionais em transição. Cadernos do REL, Brasília, n. 20, 2001.

CEFAI, Daniel; TROM, Danny (Orgs.). Les formes d'action collective. Paris: EHESS, 2001. 
CEPIK, Marco A. C. Sistemas Nacionais de Inteligência: origens, lógica de expansão e configuração atual. DADOS - Revista de Ciências Sociais, Rio de Janeiro, v. 46, n. 1, p. 75-127, 2003.

CHESNAIS, François; SERFATI, Claude; UDRY, Charles-André. El futuro del movimiento 'antimundialización'. Primeras feflexiones para una consolidación de sus fundamentos teóricos. Revista del OSAL, n. 3, enero 2001.

COLAS, Alejandro. International civil society. Cambridge: Polity Press, 2002.

COURRIER DE LA PLANÈTE. Société civile mondiale: la montée en puissance, Montpellier: Solagral, juin 2001.

D`ARCY, François. União Européia. Instituições, políticas e desafios. Rio de Janeiro: Konrad Adenauer Stiftung, 2002.

EDWARDS, Michael; GAVENTA, George. Global citizen actions. Lynne Rienner Publishers, 2001.

FOUGIER, Eddy. Le mouvement de contestation de la mondialisation. Annuaire français de relations internationales. Bruxelas: Bruylart, 2002.

GÓMEZ, José María. Entre dois fogos: o terrorismo, a guerra e os desafios do movimento social global contra-hegemônico. In: CECEÑA, Ana E.; SADER, Emir. $A$ Guerra Infinita. Hegemonia e terror mundial. Petrópolis: Vozes/CLACSO, 2002.

HARDT, Michael; NEGRI, Antonio. Império. Rio de Janeiro: Record, 200.

HOUTARD, François; POLET, François. L'autre Davos, mondialisation des résistances et des luttes. Paris: L'Harmattan, 1999.

IRIYE, Akire. Global community, the role of international organizations in the making of the Contemporary World. University of California Press, 2001.

JACKET, Pierre. La gouvernance globale à l'épreuve des contestations. In: MONTBRIAL, Thièrry; JACKET, Pierre. Rapises 2002. Paris: Dunod, 2002.

JOSSELIN, Daphné; WALLACE, William. Non-state actors. Palgrave, 2001.

KHAGRAM, Sanjeev; RIKER, James; SIKKINK, Kathryn. Restructuring World Politics, Transnational Social Movements, Networks and Norms. Minnesota: The University of Minnesota Press, 2002.

KECK, Margaret; SIKKINK, Kathryn. Activists beyond borders, international advocacy networks in international politics. Cornell University Press, 1998.

KEMP, Percy. Entrevista. Esprit, Paris, n. 10, 2003.

KEOHANE, R. International institutions: two approaches. International Studies Quarterly, v. 32, n. 4.

KEOHANE, Robert; NYE, Joseph. Transnational relations and world politics. Cambridge: Harvard University Press, 1971. 
LUCE, Mathias S. Reações inter-estatais à contestação antiglobalização na União Européia. Relatório de iniciação científica: CNPq/UFRGS. Porto Alegre: mimeo, 2003.

MARGUE, Tung-Läi. Les initiatives menées par l'union dans la lutte antiterroriste dans le cadre du troisième pilier (Justice et affaires intérieures). Revue du Droit de l'Union Européenne, n. 2, p. 261-281, 2002.

MILANI, Carlos; ARTURI, Carlos; SOLINÍS, Germán (Orgs.). Democracia e governança mundial: que regulações para o século XXI? Porto Alegre: UFRGS/UNESCO, 2002.

MONET, Jean Claude. Polícias e sociedade na Europa. São Paulo: EDUSP. (Série Polícia e Sociedade, n. 3)

MONTÉS, Jérôme. Mouvements anti-mondialisation: la crise de la démocratie representative. Etudes Internationales, v. 32, n. 4, déc. 2001.

NYE, Joseph. Take globalization protests seriously. Independent Herald Tribune, 25 Nov. 2001.

ONUF, N. G. Constructivism: a user manual. In: KUBALKOVA, V.; ONUF, N. G. et al. International relations in a constructed world. New York: M. E. Sharpe, 2001, p. $58-77$.

OSAL. Cronología de la protesta internacional 2002. Revista del OSAL, n. 9, enero 2003.

PAYE, Jean-Claude. Europol, une police autonome. Manière de Voir, janv.-fév. 2002, p. 68-70.

ROJO, Raul E. Justice et citoyenneté. La juridictionnalisation de conflits sociaux au Brésil et au Québec. Revue Juridique Thémis, Montreal, v. 38, n. 1, 2004.

SAMIZDAT.NET. Gênes, 19-20-21, juillet 2001, multitudes en marche contre l'empire. Paris: Reflex, 2002.

SEOANE, José; TADDEI, Emilio (Orgs.). Resistencias mundiales. De Seattle a Porto Alegre. Buenos Aires: CLACSO, 2001.

SMITH, J.; JOHNSTON, H. (Eds.). Globalization and resistance: transnational dimensions of social movements. Maryland: Rowman \& Littlefield, 2002.

SMOUTS, Marie-Claude (Org.). Les nouvelles relations internationales. Pratiques et theories. Paris: Presses de Sciences Po., 1998.

TARROW, S. From Lumping to Splitting: Specifying Globalization and Resistance. In: SMITH, J.; JOHNSTON, H. Globalization and Resistance, p. 229-250, 2002.

TILLY, Charles. Coerção, capital e estados europeus. São Paulo: EdUSP, 1996.

TILLY, Charles. Réclamer viva voce. Cultures et Conflits, n. 5, printemps 1992. 
TILLY, Charles. The contentious french. Cambridge: Bellknap, 1986.

VILLA, Rafael A. Duarte. Formas de influencia das ONGs na política internacional contemporânea. Revista de Sociologia e Política, Curitiba, n. 12, p. 21-33, jun. 1999.

WALLERSTEIN, Immanuel. Qué significa hoy ser un movimiento anti-sistémico? Revista del OSAL, n. 9, enero 2003.

ZIEGLER, Jean. Les nouveaux maîtres du monde et ceux qui leur résistent. Paris: Fayard, 2002. 